\title{
Clinical Usefulness of HBsAg Quantification in Patients with Chronic Hepatitis B Infection
}

\author{
Ergenekon Karagoz, ${ }^{1, *}$ and Alpaslan Tanoglu ${ }^{2}$ \\ ${ }^{1}$ Fatih Sultan Mehmet Training and Research Hospital, Istanbul, Turkey \\ ${ }^{2}$ GATA Haydarpasa Training Hospital, Department of Gastroenterology, Istanbul, Turkey \\ "Corresponding author: Ergenekon Karagoz, MD, Fatih Sultan Mehmet Training and Research Hospital, Istanbul, Turkey. E-mail: ergenekonkaragoz@hotmail.com
}

Received 2016 March 04; Revised 2017 February 08; Accepted 2017 February 10.

\begin{abstract}
Context: Quantitative hepatitis B surface antigen (qHBsAg) levels have been shown to assist the management of patients with chronic hepatitis B virus (HBV) infection and reflect the level of transcriptional activity of covalently closed circular DNA (cccDNA). It has been indicated the importance of co-operative use of qHBsAg and HBV-DNA for diagnosis and monitoring of CHB treatment. Evidence Acquisition: In order to achieve a comprehensive approach in HBsAg quantification, an extensive search was done using relevant keywords in major medical libraries to collect, categorize, and summarize data in different sections.

Results: A combination of qHBsAg $<1000 \mathrm{IU} / \mathrm{mL}$ and HBV-DNA $<2000 \mathrm{IU} / \mathrm{mL}$ can identify inactive carriers. qHBsAg levels are changed during the natural history of $\mathrm{HBV}$ infection that progressively declines from the immune tolerance to the inactive phase. Conclusions: The use of qHBsAg in chronic hepatitis B (CHB) patients may bring about important complementary information regarding HBV DNA during treatment and help predict the treatment outcome.
\end{abstract}

Keywords: Hepatitis B Surface Antigen, Chronic Hepatitis B Virus, HBV DNA

\section{Context}

HBsAg has been used for more than 40 years for diagnosing HBV infection (1). While maintaining its diagnostic utility, HbsAg has gained popularity as a result of developments in quantitative methods so that the importance of this antigen is increasing day by day. Though HBV DNA negativity is seen as the eventual target for patients, HBsAg seroconversion is the primary endpoint for patients with chronic hepatitis $\mathrm{B}(\mathrm{CHB})$. With the development of quantitative HBsAg (qHBsAg) and covalently closed circular DNA (cccDNA) measures, opportunities have been opened for new treatment methods, and with the recently developed treatment methods as a result of these discoveries, a significant increase in seroclearance of HBsAg is expected in the near future.

In the past, the methods for qualitative measurement of HBsAg being used were radioimmunoassay and "enzyme immunoassay", while quantitative measurement of HBsAg has just recently begun to be utilized. There are two main techniques for the measurement of qHBsAg. The first of these is Architect HBsAg QT (Abbot Diagnostic, Weibaden, Germany), which is a method that uses a chemiluminescent microparticle immunoassay (CLIA) and is applied frequently in clinics. Architect HBsAg QT is a diagnostic method used for quantitative measurement of HBsAg concentration in human plasma and serum using a flexible diagnostic protocol formed in two stages, called
"Chemiflex" (2). Architect HBsAg is a fully automated system that can measure HBsAg as low as $0.2 \mathrm{ng} / \mathrm{mL}$ and has a dynamic range of $0.05-250.0 \mathrm{IU} / \mathrm{mL}$. If the sample concentration is equal to or greater than $0.05 \mathrm{IU} / \mathrm{mL}$, the sample is considered reactive for HBsAg (2). The commonly used second method is Elecsys HBsAg II (Roche Diagnostic Indianapolis, IN, USA), which is a two-stage method including an incubation step (3). It is reported as a cut-off index (COI); if the index is greater than 1.0, the sample will be considered "reactive".

The primary function of HBsAg protein is to cover the surface of the virus. HBV adheres to the cell membrane using the surface protein in order to initiate the disease. HBsAg is generated from HBV DNA and is integrated into the host genome using host enzymes or by translation from transcriptionally active cccDNA. cccDNA is a minichromosome that by having a viral template regenerates the HBsAg pool to sustain CHB infection (4). For this reason, it is necessary to understand the structure and function of cccDNA for its treatment. However, the measurement of cccDNA is difficult and only liver biopsy allows for the measurement of levels of hepatic cccDNA. For this reason, search was made for a marker to reflect the quantity of cccDNA instead of only demonstrating its existence. From the conducted research studies, it was determined that serum qHBsAg reflects the level of transcriptional activity of cccDNA (5). 
In this review article, we aimed to consider recent studies on the quantification of HBsAg and its clinical use in the management of patients with $\mathrm{CHB}$ infection.

\section{Evidence Acquisition}

In order to achieve a comprehensive approach in HBsAg quantification, an extensive search was done using relevant keywords in major medical libraries to collect, categorize, and summarize data in different sections.

\section{Results}

HBsAg production is independent of the replication pathway: When Hepatitis B virus enters the hepatocyte phase, it settles on the cell nucleus, produces cccDNA and begins viral replication. Following this first and most important phase of genome replication, it proceeds with the generation of complete virion with surface antigen coming from the endoplasmic reticulum and Golgi body via replication of ccc DNA (with reverse transcription), which is followed by the produced virions secreted out of the cell by exocytosis. Another role of cccDNA is to generate surface antigen regardless of replication and then, its secretion into the circulation. On the other hand, as the viral sequence is integrated into cccDNA, it can also secrete surface antigen. As a result, HBsAg is produced by cccDNA regardless of the replication pathway. A question arises after stating this situation. Can we evaluate cccDNA better by quantitative inspection of the HBsAg level of the patient? In a study conducted by Volz et al. it was demonstrated that the level of qHBsAg is higher in patients who are HBeAg positive compared to HBeAg negative patients (6). In the same study, the level of cccDNA was also found to be higher in $\mathrm{HBeAg}$ positive patients compared to negative patients (6). It can be stated as a result of these studies that the level of HBsAg is higher proportionally to the higher levels of cccDNA in HBeAg positive CHB patients. In research conducted by Thomson et al. a positive correlation was observed between qHBsAg and HBV DNA and intrahepatic cccDNA level in HBeAg positive patients. On the other hand, there was no significant correlation in HBeAg negative patients between intrahepatic cccDNA level and HBV DNA levels, even though HBsAg production continued (7). In light of these results, it can be concluded that qHBsAg level reflects cccDNA level and its transcriptional activity.

HBsAg level in the natural history of HBV: CHB infection has four chronological phases: an initial "immune tolerance phase" identified by HBeAg positivity and high viremia accompanied by null or minimal histological destruction. The second phase is the "immune clearance phase" whereby the immune system, which identifies the virus as a foreign invader, causes severe liver cell inflammation (8). The third phase is known as the "inactive phase". Anti-HBe-positivity is seen in these patients and persistently normal alanine aminotransferase (ALT) and low HBV DNA levels $(<2000 \mathrm{IU} / \mathrm{mL}$ ) are observed in this phase. This phase is also referred to as the low replication phase. The fourth phase is characterized by late reactivation of infection with persistently or intermittently increased HBVDNA and ALT levels accompanied by progressive liver damage, so-called HBeAg-negative chronic hepatitis (8).

A question arises from the results mentioned above. For example, can the qHbsAg level be used for understanding the natural progression of Hepatitis B virus infection? Can the quantitative HBsAg level be used as an indicator for measurement of treatment response? In the medical literature, there are several studies related to whether qHBsAg levels do or do not differentiate these phases of the disease, and by evaluating these trials, it is clearly proven that qHBsAg levels vary with the natural progression of the disease and from phase to phase $(9,10)$. While qHBsAg levels differ significantly during the four phases of infection, serum quantitative HBsAg progressively declines from the immune tolerance to the inactive phase. In a study conducted on 117 naive Hepatitis B patients, the level of HBsAg was higher in patients in the immune tolerant phase. It was also stated that a decline in the level of HBsAg $>1$ $\log \mathrm{IU} / \mathrm{mL}$ is an indicator of progression from the immune tolerant phase to the immune-clearance phase, and this finding could reflect improved immune control (11). Ramachandran et al. divided 131 non-treated hepatitis B patients into two groups as $\mathrm{HBeAg}$ positive and negative, and divided the "e" positive patients as immune tolerance and immuno-clearance as well as categorized the "e" negative patients as low replication phase and " $\mathrm{e}$ " negative $\mathrm{CHB}$. HBV DNA and qHBsAg levels were found to be higher in HBeAg positive patients and a statistically significant correlation was found between these two parameters (12).

Nguyen et al. classified 220 genotype B and genotype C Asian patients with $\mathrm{CHB}$ into the four different phases of the disease and evaluated qHBsAg levels according to these phases (10). As a result of this study, the average qHBsAg levels of patients were: for the immune tolerant phase group $4.53 \log 10 \mathrm{IU} / \mathrm{mL}$, for the immune clearance phase $4.03 \log 10 \mathrm{IU} / \mathrm{mL}$, for the low replication phase $2.86 \log 10$ $\mathrm{IU} / \mathrm{ml}$, and for "e" antigen negative chronic hepatitis phase $3.35 \log 10 \mathrm{IU} / \mathrm{mL}$ (10). When the genotypes were evaluated separately, qHBsAg levels for the low replication phase group were lower in genotype $B$ patients than genotype $C$ patients. Additionally, there was no significant difference in HBsAg levels between genotypes A and D (10). On the other hand, in a comparison of all phases of $\mathrm{CHB}$, the HB- 
sAg to HBV DNA ratio was found to be highest in the low replication phase. As another result of this study, a decline in qHBsAg level was observed from the immune tolerant phase to the low replication phase (10). Compatible with this study, Jaroszewitcz et al. conducted a study on 226 European patients with $\mathrm{CHB}$ who were not undergoing antiviral treatment. They were to determine whether qHBsAg levels have an association with the natural progression of the disease. They found that the level of qHBsAg decreased as the disease progressed from the immune tolerant phase to the low replication phase (9). In addition, when the relationship of genotype with qHBsAg was evaluated, in the immune clearance phase the qHBsAg level was found to be slightly higher in genotype $\mathrm{D}$ patients than genotype A patients. Consistent with these studies, Chung et al. found out that the level of HBsAg decreased from the immune tolerant phase to the low replication phase, and in the same study, with old age, hepatocellular cancer or liver cirrhosis, it was observed that the level of qHBsAg was lower $(13,14)$.

Differentiation of inactive carriers and HBeAg negative CHB patients: qHBsAg levels can also be utilized to make a distinction between inactive HBsAg carriers and "e" antigen negative chronic hepatitis B patients. In a study conducted by Brunetto et al., it was shown that HBsAg levels were significantly lower in inactive carriers. Additionally, the combined single point quantification of $\mathrm{HBsAg}(<$ $1000 \mathrm{IU} / \mathrm{mL}$ ) and HBV-DNA ( $<$ or $=2000 \mathrm{IU} / \mathrm{mL}$ ) identified inactive carriers with $94.3 \%$ diagnostic accuracy, $91.1 \%$ sensitivity, $95.4 \%$ specificity, $87.9 \%$ positive predictive value, and $96.7 \%$ negative predictive value (15). In another study, the levels of qHBsAg were evaluated in 104 chronic hepatitis B patients with genotype C. In that study, inactive carriers and envelope antigen negative hepatitis B (HBeAg negative $\mathrm{CHB}$ ) patients were compared according to qHBsAg levels. In the inactive HBsAg carriers, the level of HBsAg was lower compared to HBeAg-negative $\mathrm{CHB}$ patients (16). On the other hand, Sali et al. showed that serum HBsAg level was different among inactive and active HBeAg-negative chronic HBV-infected individuals in a recent study (17). Moreover, single point HBsAg quantification did not have enough sensitivity and specificity for diagnosis of HBeAgnegative chronic hepatitis B clinical stages (17).

qHBsAg and Genotypes: HBV genotypes can also affect quantitative HBsAg levels and their kinetics. Additionally, HBsAg decline varies with HBV genotype in PEG-IFN treated patients in response to treatment. Jaroszewitcz et al. demonstrated that the qHBsAg titer was significantly higher in genotypes A and D compared to other genotypes (especially in the Mediterranean region and Europe) $(9,18)$. Brunetto et al. investigated whether on-treatment kinetics (peginterferon alfa-2a) of HBsAg serum levels varies by HBV genotype (19). They demonstrated that baseline qHB-
sAg levels were significantly higher for A than for B, C, and $D$ genotypes $(\mathrm{P}<0.05)$. On-treatment HBsAg kinetics varied according to HBV genotype. The difference between responders and non-responders was greatest for genotype $\mathrm{A}$ in the weeks 12 - 24; and for genotypes B and D from baseline to week 12; there was no significant difference over any timeframe for genotype $\mathrm{C}$. High positive predictive values for long-term virological response could be obtained by applying end-of-treatment genotype-specific cut-offs: $75 \%$, $47 \%, 71 \%$, and $75 \%$ for genotypes $\mathrm{A}(<400 \mathrm{IU} / \mathrm{mL}), \mathrm{B}(<50$ $\mathrm{IU} / \mathrm{mL}), \mathrm{C}(<75 \mathrm{IU} / \mathrm{mL})$, and $\mathrm{D}(<1000 \mathrm{IU} / \mathrm{mL})$, respectively (19). In another study evaluating qHBsAg kinetics for the different phases of CHB infection, it was demonstrated that although qHBsAg levels were higher in CHB patients with genotype D compared to genotype A patients, there was no statistically significant difference between these two genotypes in the immune clearance phase (4.46 vs. $4.3 \log 10$ $\mathrm{IU} / \mathrm{mL}, \mathrm{P}=0.18$ ). Although a difference in $\mathrm{qHBsAg}$ levels was found between genotypes in $\mathrm{HBeAg}$ negative $\mathrm{CHB}$ patients, the difference was not statistically significant.

Correlation between qHBsAg and HBV DNA levels: There are also many studies investigating the correlation between qHBsAg and HBV DNA levels. Most of those studies demonstrated a significant relationship between these markers. Ganji et al. investigated the correlation between HBsAg quantitative assay results and HBV DNA levels in chronic HBV patients. Although a significant relationship was found in HBeAg positive patients, no meaningful relationship was found in "e" negative patients (8). In another study conducted by Antaki et al. a significant correlation was shown between HBV DNA and qHBsAg levels in $\mathrm{CHB}$ patients who were immune tolerant and HBeAgnegative $\mathrm{CHB}$ patients. In other words, a correlation between serum HBV DNA levels and qHBsAg titers does not appear except for immune tolerant and HBeAg-negative CHB patients (20). Additionally, Alghamdi et al. demonstrated a significant relationship between these markers in HBeAg negative patients and stated that they could be considered as predictor if they are used together (21). Gunal et al. revealed a significant correlation between HBV DNA levels and ALT and qHBsAg levels (22).

Relationship between quantitative HBsAg levels and HBsAg seroclearance: quantitative HBsAg levels can provide a good prediction for HBsAg seroclearance. In a study conducted on 68 HBeAg negative patients, it was demonstrated that a reduction of HBsAg of $>1 \log \mathrm{IU} / \mathrm{mL}$ could reflect improved immune control (11). In another study, in a comparison of $\mathrm{CHB}$ patients with low and high levels of qHBsAg, low serum levels of HBsAg, alone or in combination with HBV DNA levels, one year after HBeAg seroconversion could predict HBsAg seroclearance in patients with HBV genotype B or C infection (23). In another study con- 
ducted by Arai et al. evaluating 423 chronic hepatitis B patients diagnosed as HBsAg positive between 1985 and 2008 , it was stated that the possibility of HBsAg loss was significantly higher for patients that had lower baseline qHBsAg levels (24).

Consideration of HBV DNA and qHBsAg together can also provide an insight into the evaluation of HBsAg seroclearance (25). In a previous study, it was stated that these values could be used for "HBsAg" seroconversion evaluation for 5-year follow-up as 10\% and for 8-year follow-up as $23 \%(26,27)$. In another study on 102 HBeAg-negative patients, a cutoff of $2040 \mathrm{IU} / \mathrm{mL}$ of HBsAg had high sensitivity (87\%) and high specificity (75\%) for diagnosing the inactive carrier state (28). In a different study, it was shown that the level of qHBsAg is a more effective and convenient parameter for demonstrating active HBV infection compared to HBV DNA and qualitative HBsAg (29).

qHBsAg levels and liver histopathology: In the medical literature, there are also investigations assessing the relationship between liver histopathology and qHBsAg. In most of these studies, lower HBsAg level was found to reflect the status of advanced liver fibrosis, especially in HBeAg positive chronic hepatitis B subjects. In contrast to these studies, there was no significant relationship between liver histology and qHBsAg levels in only a few studies with small sample size. For instance, Demiroren et al. conducted a study on $56 \mathrm{HBeAg}$ positive patients receiving interferon alpha $2 \mathrm{~b}$ treatment and found no meaningful relationship between qHBsAg level and fibrosis degree (30). Contrary to what was noted in that study, it was demonstrated that qHBsAg levels specifically identified significant fibrosis in treatment-naive HBeAg-positive HBV carriers in another study conducted with a larger patient group (31). In another investigation carried out by Farnik et al. with analogs of nucleotides and nucleosides, the M-30 apoptosis epitope and its quantitative levels before and after treatment were evaluated, and a significant decrease in HBV DNA parallel to qHBsAg was observed at the 24th week of treatment. M30-apoptotic activity was also significantly correlated with M65-necrosis and fibrosis (32). With this result, the study took its place in the medical literature as showing declined cell death parameters in relation to a decrease in HBV-DNA and HBsAg levels, indicating a reduction in overall cell death activity during treatment and supporting the idea that response to oral antiviral therapy reduces necroinflammatory activity and the progression of liver disease (32).

qHBsAg levels and hepatocellular carcinoma: In the medical literature, it has been shown that qHBsAg may be used as an indicator for evaluating the risk of HCC occurrence. Especially among $\mathrm{CHB}$ patients with low viral load, qHBsAg can be considered as an indicator of HBV DNA for predicting HCC occurrence. In a study conducted in Taiwan on 3411 hepatitis B patients, it was stated that with an increase in qHBsAg levels, the risk of HCC occurrence also increased (33). In the same study on 2688 non-cirrhotic CHB patients followed up for 14.7 years, it was found that among low viral loaded patients, higher levels of qHBsAg increased the HCC occurrence risk (33). Moreover, qHBsAg levels can also be used in the post-treatment follow-up period. Additionally, it has been suggested that individuals with pre-treatment low baseline HBsAg and qHBsAg levels have a better response to CHB treatment (34-36).

Monitoring therapy: we all know that interferon treatment destroys infected hepatocytes; thus, there is a decrease in cccDNA levels and as a result, lower HBsAg levels are observed. In a study carried out by Demiroren et al. $56 \mathrm{HBeAg}$ positive children treated with interferon alfa-2b were examined for their pre-treatment and post-treatment qHBsAg levels and a significant difference was observed (30). In another study, Brunetto et al. considered the possibility of qHBsAg seroclearance as 30\% for patients that show more than 1 log decrease in qHBsAg levels after interferon treatment within 3 years. If the decrease was less than $1 \mathrm{log}$, the possibility of HbsAg seroclearance was 3\% after 3 years (37). In another study, HBeAg seroconversion ratios were $54 \%$ and $57 \%$ at the post-treatment 12 th and 24th weeks of peg-IFN alfa-2A therapy if the qHBsAg levels were below $1500 \mathrm{IU} / \mathrm{mL}$ (38). The NEPTUNE study revealed that "e" seroconversion ratio after peg-IFN treatment was higher among patients with a quantitative HBsAg level of $<$ $1500 \mathrm{IU} / \mathrm{mL}$ compared to patients with HBsAg levels $>1500$ $\mathrm{IU} / \mathrm{mL}(\mathrm{P}<0.005)$ (39).

In a study conducted by Rijckbrost et al. on 102 pegIFN alfa-2A treated genotype D patients, it was stated that if there is no decrease in HBsAg and HBV DNA levels, the possibility of treatment response will be $0 \%$, which means that the NPV is $100 \%$ (40). Moreover, it has been stated that in peg-IFN alfa-2A treated $\mathrm{HBeAg}$ positive $\mathrm{CHB}$ patients, if there is no decrease in levels of qHBsAg, or the qHBsAg levels are more than $20,000 \mathrm{IU} / \mathrm{ml}$, this situation can be judged as treatment failure; and this can be considered to be a powerful negative predictor $(18,41,42)$. On the other hand, among HBeAg negative patients, no decrease in $\mathrm{HB}$ sAg levels at the 12th week or a decrease of less than 2 logs for HBV DNA should be considered as negative predictor in the response to peg-IFN treatment and the treatment should be stopped at the 12th week (18). Thus, as stated above, response to $\mathrm{CHB}$ treatment among HBeAg positive and negative patients is closely associated with decreased qHBsAg levels with interferon based treatments $(43,44)$.

Beneficial use of quantitative HBsAg as a treatment follow-up marker for CHB patients under oral antiviral treatment has also been demonstrated in previous re- 
search. However, in these studies, the decrease in qHBsAg levels under oral antiviral CHB treatment was slower compared to patients under interferon treatment. Moreover, it was also stated that response to oral antiviral therapy will be higher if the baseline qHBsAg level is lower (26). Reijinders et al. evaluated $\mathrm{CHB}$ patients receiving peg-IFN alfa$2 \mathrm{~A}$ or entacavir treatment at the 48th week of treatment, and found that there was a significant decline in qHBsAg levels in the interferon group compared to the entacavir group (45). In two different studies of CHB patients under entecavir treatment, it has been shown that if "e" seroconversion is observed, a statistically significant decrease in qHBeAg levels can be achieved at the 96th week of treatment $(45,46)$. In another study of CHB patients under telbuvidine treatment, it was shown that if there was a decrease in qHBsAg levels greater than $1 \log \mathrm{IU} / \mathrm{mL}$ in the first year of treatment, this rapid decline would be a good predictor for subsequent HBsAg clearance (47). In another study conducted on HBeAg positive $\mathrm{CHB}$ patients under entecavir treatment, Lee et al. suggested that a qHBsAg level $<3000 \mathrm{IU} / \mathrm{mL}$ at the 3rd month and HBV DNA negativity at the 12th month can be considered as independent predictive factors for estimating HBeAg seroconversion (48). Kim et al. evaluated qHBsAg levels in $48 \mathrm{CHB}$ patients receiving lamivudine or entacavir treatment at the 6th month, 1st, 2nd, 3rd, 4th, and 5th years and made a conclusion that a meaningful decrease in qHBsAg levels can be achieved only on long-term follow-up (4th year and thereafter) (49). Fung et al. evaluated whether there is a difference in qHBsAg levels between pre-treatment and the 2 nd year of treatment for $\mathrm{CHB}$ patients already under entrecavir treatment for 2 years (50). Although negativity was obtained in HBV DNA levels, they reported that there was no significant decrease in qHBsAg levels (50). In a different study, serum qHBsAg levels of $42 \mathrm{HBeAg}$ negative patients under lamivudine treatment were observed and it was determined that if there was not a $0.7 \log \mathrm{IU} / \mathrm{mL}$ decrease in qHBsAg level at the 6th month of treatment, the possibility of virological breakthrough can be increased to $90 \%$. In the same study, if the patient responded to lamivudine treatment, an important decrease in qHBsAg levels in the follow-up period was noticed (51). In another study that included $21 \mathrm{HBeAg}$ positive and $10 \mathrm{HBeAg}$ negative patients under oral antiviral treatment, qHBsAg levels were tested at the 12th, 24th, and 48th weeks of therapy, and a significant decrease in qHBsAg levels was noticed among HBeAg positive patients (52). Compatible with this research, Bakhshizadeh et al. demonstrated that HBeAg-negative patients have better virological responses than HBeAg-positive ones with tenofovir Tenofovir disoproxil fumarate (TDF) treatment (53). Although TDF treatment showed no HBeAg and HBsAg loss or seroconversion in those patients, it strongly decreased the HBsAg level in both HBeAg-negative and exclusively HBeAg-positive patients (53). In a study of $42 \mathrm{CHB}$ under telbuvidine treatment, it was stated that if the decrease in qHBsAg levels is rapid, HBsAg loss will be more prominent (54). In a different study, age and qHBsAg levels were considered to be useful predictors for stopping entacavir treatment for $\mathrm{CHB}$ patients with genotype $\mathrm{C}$ who are under entacavir treatment for two years. Moreover, HBeAg positive patients over 40 years old with a baseline level of qHBsAg greater than $4500 \mathrm{IU} / \mathrm{ml}$ were considered to have increased risk of relapse after treatment. In addition, HBeAg negative patients under 55 years of age having a baseline level of qHBsAg less than $190 \mathrm{IU} / \mathrm{mL}$ after 2 years of treatment were considered to have a decreased risk of relapse (55). In another study that included 143 telbuvidine treated patients, a decrease of more than $0.5 \log \mathrm{IU} / \mathrm{mL}$ in the qHBsAg level at the 3rd month of treatment was suggested to be related to a significant loss of qHBsAg at the 2nd year of treatment (56). Compatible with this research, Peng et al. studied long-term nucleoside or nucleotide analog treated CHB patients, and concluded that a decrease in qHBsAg levels would be significant between 4 and 7 years of therapy. Moreover, having a low level of pre-treatment HBsAg and a fast decrease in HBsAg level at the 3rd month of treatment can be considered as a predictor of therapy response (57). In light of these findings, it would be rational to expect a significant decrease in HBsAg level and "S" antigen loss with the use of oral antivirals in long-term follow-up. In another study of $120 \mathrm{HBV}$ and HCV co-infected patients under peg-IFN alfa-2A and ribavirin therapy, the average baseline qHBsAg level was $120 \mathrm{IU} / \mathrm{mL}$ and a significant decrease in qHBsAg level was observed after treatment. Lower levels of baseline HBsAg were found to be closely associated with HBsAg seroclearance (58).

Recently there are new studies comparing the efficiency of peg-IFN add-on therapies with oral antiviral monotherapies. In a study by Xie et al. peg-IFN was added for a period of 48 weeks for patients who were under entacavir or tenofovir treatment and compared with patients under NA monotherapy in terms of serological response and HBeAg seroconversion. The seroconversion of HBeAg and decreased qHBsAg level were found to be statistically significant in patients under Peg-IFN add-on treatment for 48 weeks than patients with entacavir or tenofovir monotherapy (59). In a different study, patients under peg-IFN alfa $2 \mathrm{~A}$ and tenofovir combination treatment were compared with those under monotherapies in terms of HBsAg decrease. Post-treatment levels of qHBsAg for the combined therapy group were significantly lower and HBsAg decrease was prominently higher (60). Due to the ability to suppress HBV DNA levels quickly as well as being potent, having less side effects and lower resistance profile, 
oral antiviral agents are preferred over interferon treatment throughout the world $(50,61)$. However, the superior suppression effects of the interferons in HBsAg quantification and cccDNA level have once again shifted physicians to interferon-based treatments. In a recent study by Lucifora et al., it was stated that interferon decreases cccDNA levels by activating the lymphotoxin-B receptor without generating hepatotoxic effects. This activation is related to $\mathrm{APOBEC} 3 \mathrm{~A}$ and $\mathrm{APOBEC} 3 \mathrm{~B}$ cytidine deaminase upregulation (62).

Sodium taurocholate cotransporting polypeptide (NTCP) works as a receptor for HBV and this finding has led scientists to develop better treatment models by helping them have a better understanding of virus pathogenesis (63). An example of the mechanism mentioned above is the discovery of the agent called Myrcludex-B, which inhibits hepatitis B virus entry into cells by targeting NTCP. It has been shown that Myrcludex-B efficiently and successfully blocks intrahepatic virus in hepatitis B infected rats. On the other hand, new studies of cccDNA-targeting treatments are ongoing. These treatments include cytokines (interferon, etc.), lymphotoxin-b receptor agonists (LtbRa), DNA cleavage enzymes and siRNAs (64). In other words, although it is not stated in the guidelines, a combination of immune modulation therapies (pegylated interferon, etc.) and viral suppression treatments can be more effective via suppression of viral load and cccDNA.

\section{Conclusions}

In the medical literature, there are very limited studies on qHBsAg in HBV and HDV co-infected patients and further research will provide a positive contribution for clinicians to monitor treatment. In case of mutation-related reactivation, qHBsAg may provide a more objective and additional contribution compared to HBV DNA. Thus, comprehensive studies on this subject are needed. On the other hand, there are also limited studies examining the relationship between mutated chronic HBV infection and qHBsAg levels. Further research on this topic may provide more optimal CHB treatment and monitoring. Another important point is the addition of qHBsAg to the algorithms used in treatment guidelines. Guidelines such as EASL and NICE indicate the importance of co-operative use of qHBsAg and HBV-DNA for diagnosis and monitoring of CHB treatment. Quantitative HBsAg, which is the only non-invasive tool for determining cccDNA activity, is a promising indicator that enlightens clinicians to the possibility of CHB infection cure with the suppression of both viral load and cccDNA by the use of pegylated interferon + nucleoside analogs and/or new immune modulator treatment methods + viral suppressive treatments. Quantitative HBsAg, with its ability to open new grounds for genomic discoveries related to Hepatitis B, will make it possible to develop safe and more efficient treatment strategies for clinicians and researchers.

\section{Footnote}

Conflict of Interest: The authors report no conflict of interest.

\section{References}

1. Zhang YM, Yang YD, Jia HY, Zeng LY, Yu W, Zhou N, et al. HBsAg levels in HBeAg-positive chronic hepatitis B patients with different immune conditions. World J Gastroenterol. 2014;20(15):4407-13. doi: 10.3748/wjg.v20.i15.4407. [PubMed: 24764680].

2. Deguchi M, Yamashita N, Kagita M, Asari S, Iwatani Y, Tsuchida $\mathrm{T}$, et al. Quantitation of hepatitis B surface antigen by an automated chemiluminescent microparticle immunoassay. J Virol Methods. 2004;115(2):217-22. [PubMed: 14667538].

3. Maylin S, Boyd A, Delaugerre C, Zoulim F, Lavocat F, Simon F, et al. Comparison between Elecsys HBsAg II and Architect HBsAg QT assays for quantification of hepatitis B surface antigen among patients coinfected with HIV and hepatitis B virus. Clin Vaccine Immunol. 2011:CVI 05454-11.

4. Dandri M, Locarnini S. New insight in the pathobiology of hepatitis B virus infection. Gut. 2012;61 Suppl 1:i6-17. doi: 10.1136/gutjnl-2012302056. [PubMed: 22504921].

5. Karagoz E. Do hepatic flares really promote rapid decline of serum hepatitis B surface antigen (HBsAg) in patients with HBsAg seroclearance?. Hepatol Res. 2016;46(7):719. doi: 10.1111/hepr.12630. [PubMed: 26620924].

6. Volz T, Lutgehetmann M, Wachtler P, Jacob A, Quaas A, Murray JM, et al. Impaired intrahepatic hepatitis $B$ virus productivity contributes to low viremia in most HBeAg-negative patients. Gastroenterology. 2007;133(3):843-52. doi: 10.1053/j.gastro.2007.06.057. [PubMed: 17854594].

7. Thompson AJ, Nguyen T, Iser D, Ayres A, Jackson K, Littlejohn M, et al. Serum hepatitis B surface antigen and hepatitis B e antigen titers: disease phase influences correlation with viral load and intrahepatic hepatitis B virus markers. Hepatology. 2010;51(6):1933-44. doi: 10.1002/hep.23571. [PubMed: 20512987].

8. Ganji A, Esmaeilzadeh A, Ghafarzadegan K, Helalat H, Rafatpanah $\mathrm{H}$, Mokhtarifar A. Correlation between HBsAg quantitative assay results and HBV DNA levels in chronic HBV. Hepat Mon. 2011;11(5):342-5. [PubMed: 22087158].

9. Jaroszewicz J, Calle Serrano B, Wursthorn K, Deterding K, Schlue J, Raupach R, et al. Hepatitis B surface antigen (HBsAg) levels in the natural history of hepatitis B virus (HBV)-infection: a European perspective. J Hepatol. 2010;52(4):514-22. doi: 10.1016/j.jhep.2010.01.014. [PubMed: 20207438].

10. Nguyen T, Thompson AJ, Bowden S, Croagh C, Bell S, Desmond PV, et al. Hepatitis B surface antigen levels during the natural history of chronic hepatitis B: a perspective on Asia. J Hepatol. 2010;52(4):50813. doi: 10.1016/j.jhep.2010.01.007. [PubMed: 20206400].

11. Chan HL, Wong VW, Wong GL, Tse CH, Chan HY, Sung JJ. A longitudinal study on the natural history of serum hepatitis B surface antigen changes in chronic hepatitis B. Hepatology. 2010;52(4):1232-41. doi: 10.1002/hep.23803. [PubMed: 20648555].

12. Ramachandran J, Ismail AM, Chawla G, Fletcher GJ, Goel A, Eapen CE, et al. Serum HBsAg quantification in treatment-naive Indian patients 
with chronic hepatitis B. Indian J Gastroenterol. 2014;33(2):131-5. doi: 10.1007/s12664-013-0395-1. [PubMed: 24052375].

13. Chung KH, Kim W, Kim BG, Lee HY, Jin E, Cho Y, et al. Hepatitis B Surface Antigen Quantification across Different Phases of Chronic Hepatitis B Virus Infection Using an Immunoradiometric Assay. Gut Liver. 2015;9(5):657-64. doi: 10.5009/gnl14188. [PubMed: 25717049].

14. Jia W, Qi X, Ji YY, Xun YH, Wang H, Zhang WH, et al. Low Serum Hepatitis B Surface Antigen Level Predicts Compensated Cirrhosis Caused by Chronic Hepatitis B in HBeAg Positive Patients in East China. Hepat Mon. 2015;15(8):ee29183. doi: 10.5812/hepatmon.29183. [PubMed: 26322110].

15. Brunetto MR, Oliveri F, Colombatto P, Moriconi F, Ciccorossi P, Coco B, et al. Hepatitis B surface antigen serum levels help to distinguish active from inactive hepatitis B virus genotype D carriers. Gastroenterology. 2010;139(2):483-90. doi: 10.1053/j.gastro.2010.04.052. [PubMed: 20451520].

16. Park H, Lee JM, Seo JH, Kim HS, Ahn SH, Kim DY, et al. Predictive value of HBsAg quantification for determining the clinical course of genotype C HBeAg-negative carriers. Liver Int. 2012;32(5):796-802. doi: 10.1111/j.1478-3231.2011.02693.x. [PubMed: 22128792].

17. Sali S, Sharafi H, Alavian SH, Alavian SM, Etesam F, Salimi S, et al. Can serum level of HBsAg differentiate HBeAg-negative chronic hepatitis B from inactive carrier state?.Diagn Microbiol Infect Dis. 2015;82(2):1149. doi: 10.1016/j.diagmicrobio.2015.02.005. [PubMed: 25863529].

18. Sonneveld MJ, Hansen BE, Piratvisuth T, Jia JD, Zeuzem S, Gane E, et al. Response-guided peginterferon therapy in hepatitis $B$ e antigenpositive chronic hepatitis B using serum hepatitis B surface antigen levels. Hepatology. 2013;58(3):872-80. doi: 10.1002/hep.26436. [PubMed: 23553752].

19. Brunetto MR, Marcellin P, Cherubini B, Yurdaydin C, Farci P, Hadziyannis SJ, et al. Response to peginterferon alfa-2a (40KD) in HBeAg-negative CHB: on-treatment kinetics of HBsAg serum levels vary by HBV genotype. J Hepatol. 2013;59(6):1153-9. doi: 10.1016/j.jhep.2013.07.017. [PubMed: 23872601].

20. Antaki N, Zeidane N, Alhaj N, Hadad M, Baroudi O, Antaki F, et al. HBsAg titers in the different phases of hepatitis B infection in Syrian patients. J Clin Virol. 2012;53(1):60-4. doi: 10.1016/j.jcv.2011.10.004. [PubMed: 22079974].

21. Alghamdi A, Aref N, El-Hazmi M, Al-Hamoudi W, Alswat K, Helmy A, et al. Correlation between hepatitis B surface antigen titers and HBV DNA levels. Saudi J Gastroenterol. 2013;19(6):252-7. doi: 10.4103/13193767.121035. [PubMed: 24195978].

22. Gunal O, Barut S, Etikan I, Duygu F, Tuncel U, Sunbul M. Relation between serum quantitative HBsAg, ALT and HBV DNA levels in HBeAg negative chronic HBV infection. Turk J Gastroenterol. 2014;25 Suppl 1:142-6. doi: 10.5152/tjg.2014.5711. [PubMed: 25910293].

23. Tseng TC, Liu CI, Su TH, Wang CC, Chen CL, Chen PJ, et al. Serum hepatitis $B$ surface antigen levels predict surface antigen loss in hepatitis B e antigen seroconverters. Gastroenterology. 2011;141(2):517-25. doi: 10.1053/j.gastro.2011.04.046. [PubMed: 21672542] 525 e1-2.

24. Arai M, Togo S, Kanda T, Fujiwara K, Imazeki F, Yokosuka O. Quantification of hepatitis B surface antigen can help predict spontaneous hepatitis B surface antigen seroclearance. Eur J Gastroenterol Hepatol. 2012;24(4):414-8. doi: 10.1097/MEG.0b013e328350594d. [PubMed: 22273987].

25. Liu J, Yang HI, Lee MH, Jen CL, Batrla-Utermann R, Lu SN, et al. Serum Levels of Hepatitis B Surface Antigen and DNA Can Predict Inactive Carriers With Low Risk of Disease Progression. Hepatology. 2016;64(2):381-9. doi:10.1002/hep.28552. [PubMed: 27079545].

26. Vigano M, Lampertico P. Clinical implications of HBsAg quantification in patients with chronic hepatitis B. Saudi J Gastroenterol. 2012;18(2):81-6. doi: 10.4103/1319-3767.93805. [PubMed: 22421711].

27. Chan HLY, Wong GLH, Tse CH, Chan HY, Wong VWS. 360 Definition of Inactive Hepatitis B Carrier by Serum Hbsag and Hbv DNA Levels - a Long-Term Follow-up Study on Hbsag Seroclearance. J Hepatol. 2011;54:S144-5. doi: 10.1016/s0168-8278(11)60362-0.
28. Yakut M, Bektas M, Seven G, Kabaçam G, Karatayli E, Karatayli S, et al. 398 Characterization of the Inactive Hbsag Carrier State with 3 Year Follow-Up. J Hepatol. 2011;54:S159. doi: 10.1016/s0168-8278(11)60400-5.

29. Kuo YH, Chang KC, Wang JH, Tsai PS, Hung SF, Hung CH, et al. Changing serum levels of quantitative hepatitis B surface antigen and hepatitis $B$ virus DNA in hepatitis B virus surface antigen carriers: a follow-up study of an elderly cohort. Kaohsiung J Med Sci. 2015;31(2):102-7. doi: 10.1016/j.kjms.2014.11.002. [PubMed: 25645989].

30. Demiroren K, Kocamaz H, Dogan Y. The importance of the serum quantitative levels of hepatitis $B$ surface antigen and hepatitis $B$ e antigen in children with chronic hepatitis B. Turk J Gastroenterol. 2015;26(1):36-41. doi: 10.5152/tjg.2015.4636. [PubMed: 25698269].

31. Xun YH, Zang GQ, Guo JC, Yu XL, Liu H, Xiang J, et al. Serum hepatitis $B$ surface antigen quantification as a useful assessment for significant fibrosis in hepatitis B e antigen-positive hepatitis B virus carriers. J Gastroenterol Hepatol. 2013;28(11):1746-55. doi: 10.1111/jgh.12304. [PubMed: 23800140].

32. Farnik H, Lange CM, Hofmann WP, Berger A, Allwinn R, Welker MW, et al. Nucleos(t)ide analogue treatment reduces apoptotic activity in patients with chronic hepatitis B. J Clin Virol. 2011;52(3):204-9. doi: 10.1016/j.jcv.2011.08.009. [PubMed: 21903459].

33. Tseng TC, Liu CJ, Yang HC, Su TH, Wang CC, Chen CL, et al. High levels of hepatitis B surface antigen increase risk of hepatocellular carcinoma in patients with low HBV load. Gastroenterology. 2012;142(5):1140-1149 e3. doi: 10.1053/j.gastro.2012.02.007. [PubMed: 22333950] quiz e13-4.

34. Chen $\mathrm{CH}$, Chiu YC, Lu SN, Lee CM, Wang JH, Hu TH, et al. Serum hepatitis B surface antigen levels predict treatment response to nucleos(t)ide analogues. World J Gastroenterol. 2014;20(24):7686-95. doi: 10.3748/wjg.v20.i24.7686. [PubMed: 24976706].

35. Chen $\mathrm{CH}$, Lu SN, Hung CH, Wang JH, Hu TH, Changchien CS, et al. The role of hepatitis B surface antigen quantification in predicting HBsAg loss and HBV relapse after discontinuation of lamivudine treatment. J Hepatol. 2014;61(3):515-22. doi: 10.1016/j.jhep.2014.04.029. [PubMed: 24798617].

36. Su TH, Hsu CS, Chen CL, Liu CH, Huang YW, Tseng TC, et al. Serum hepatitis B surface antigen concentration correlates with HBV DNA level in patients with chronic hepatitis B.AntivirTher. 2010;15(8):1133-9. doi: 10.3851/IMP1696. [PubMed: 21149920].

37. Brunetto MR, Moriconi F, Bonino F, Lau GK, Farci P, Yurdaydin C, et al. Hepatitis B virus surface antigen levels: a guide to sustained response to peginterferon alfa-2a in HBeAg-negative chronic hepatitis B. Hepatology. 2009;49(4):1141-50. doi: 10.1002/hep.22760. [PubMed: 19338056].

38. Piratvisuth T, Marcellin P, Popescu M, Kapprell HP, Rothe V, Lu ZM. Hepatitis B surface antigen: association with sustained response to peginterferon alfa-2a in hepatitis B e antigen-positive patients. Hepatol Int. 2013;7(2):429-36. doi: 10.1007/s12072-011-9280-0. [PubMed: 21701902].

39. Gane E, Jia JD, Han KH, Tanwandee T, Chuang WL, Marcellin P, et al. 69 neptune study: On-treatment hbsag level analysis confirms prediction of response observed in phase 3 study of peginterferon alfa-2a in hbeag-positive patients.J Hepatol. 2011;54:S31.

40. Rijckborst V, Hansen BE, Cakaloglu Y, Ferenci P, Tabak F, Akdogan $\mathrm{M}$, et al. Early on-treatment prediction of response to peginterferon alfa-2a for HBeAg-negative chronic hepatitis B using HBsAg and HBV DNA levels. Hepatology. 2010;52(2):454-61. doi: 10.1002/hep.23722. [PubMed: 20683945].

41. Piratvisuth T, Marcellin P. Further analysis is required to identify an early stopping rule for peginterferon therapy that is valid for all hepatitis B e antigen-positive patients. Hepatology. 2011;53(3):1054-5. doi: 10.1002/hep.24136. [PubMed: 21374671] author reply 1055.

42. Martinot-Peignoux M, Asselah T, Marcellin P. HBsAg quantification to optimize treatment monitoring in chronic hepatitis B patients. Liver Int. 2015;35 Suppl 1:82-90. doi: 10.1111/liv.12735. [PubMed: 25529092]. 43. Moucari R, Mackiewicz V, Lada O, Ripault MP, Castelnau C, Martinot- 
Peignoux M, et al. Early serum HBsAg drop: a strong predictor of sustained virological response to pegylated interferon alfa2a in HBeAg-negative patients. Hepatology. 2009;49(4):1151-7. doi: 10.1002/hep.22744. [PubMed: 19115222].

44. Janssen HL, Kerhof-Los CJ, Heijtink RA, Schalm SW. Measurement of HBsAg to monitor hepatitis B viral replication in patients on alpha-interferon therapy. Antiviral Res. 1994;23(3-4):251-7. [PubMed: 8042863].

45. Reijnders JG, Rijckborst V, Sonneveld MJ, Scherbeijn SM, Boucher CA, Hansen BE, et al. Kinetics of hepatitis B surface antigen differ between treatment with peginterferon and entecavir. J Hepatol. 2011;54(3):449-54. doi:10.1016/j.jhep.2010.07.046. [PubMed: 21112655].

46. Zoulim F, Carosi G, Greenbloom S, Mazur W, Nguyen T, Jeffers L, et al. Quantification of HBsAg in nucleos(t)ide-naive patients treated for chronic hepatitis B with entecavir with or without tenofovir in the BELOW study. J Hepatol. 2015;62(1):56-63. doi: 10.1016/j.jhep.2014.08.031. [PubMed: 25176615].

47. Wursthorn K, Jung M, Riva A, Goodman ZD, Lopez P, Bao W, et al. Kinetics of hepatitis B surface antigen decline during 3 years of telbivudine treatment in hepatitis B e antigen-positive patients. Hepatology. 2010;52(5):1611-20. doi: 10.1002/hep.23905. [PubMed: 20931556].

48. Lee JH, Kim SJ, Ahn SH, Lee J, Park Y, Kim HS. Correlation between quantitative serum HBsAg and HBV DNA test in Korean patients who showed high level of HBsAg. J Clin Pathol. 2010;63(11):1027-31. doi: 10.1136/jcp.2010.078832. [PubMed: 20870658].

49. Kim JH, Choi YJ, Moon HW, Ko SY, Choe WH, Kwon SY. HBsAg level and clinical course in patients with chronic hepatitis B treated with nucleoside analogue: five years of follow-up data. Clin Mol Hepatol. 2013;19(4):409-16. doi: 10.3350/cmh.2013.19.4.409. [PubMed: 24459646].

50. Fung J, Lai CL, Young J, Wong DK, Yuen J, Seto WK, et al. Quantitative hepatitis B surface antigen levels in patients with chronic hepatitis B after 2 years of entecavir treatment. Am J Gastroenterol. 2011;106(10):1766-73. doi:10.1038/ajg.2011.253. [PubMed: 21826112].

51. Gramenzi A, Loggi E, Micco L, Cursaro C, Fiorino S, Galli S, et al. Serum hepatitis B surface antigen monitoring in long-term lamivudinetreated hepatitis B virus patients. J Viral Hepat. 2011;18(10):e468-74. doi:10.1111/j.1365-2893.2011.01473.x. [PubMed: 21914065].

52. Kandemir OD, Gultekin O, Unlu S. Kinetics of hepatitis B surface antigen with nucleo(s)tide analogues. 24th Annual Conference of the Asian Pacific Association for the study of the liver; 2015. Istanbul.

53. Bakhshizadeh F, Hekmat S, Keshvari M, Alavian SM, Mostafavi E, Keivani $\mathrm{H}$, et al. Efficacy of tenofovir disoproxil fumarate therapy in nucleoside-analogue naive Iranian patients treated for chronic hepatitis B. Hepat Mon. 2015;15(5):ee25749. doi: 10.5812/hepatmon.15(5)2015.25749. [PubMed: 26045705].

54. Zhang XLLG, Huang ZY. Kinetics of hepatitis B surface antigen decline during 3 years of telbivudine treatment in hepatitis B e antigen neg ative patients in Changzhou China. 24th Annual Conference of the Asian Pacific Association for the study of the liver; 2015. Istanbul.

55. Chen CLC, Hung C, Hu T, Wang J, Lu S. Combination of age and hepatitis B surface antigen levels in predicting hbv relapse after cessation of entecavir treatment. 24th Annual Conference of the Asian Pacific Association for the study of the liver; 2015. Istanbul. .

56. Yu HLK, Hsu P. Changes of hepatitis B surface antigen levels in chronic hepatitis B patients with telbivudine treatment for more than 2 years. 24th Annual Conference of the Asian Pacific Association for the study of the liver; 2015. Istanbul.

57. Cheng-Yuan Peng HC, Wen-Pang S, Chia-Hsin. L. , Po-Heng C, ShengHung C. Kinetics of quantitative serum hbsag decline during seven yearsof nucleos(t)ide analogue therapy in chronic hepatitis B patients. 24th Annual Conference of the Asian Pacific Association for the study of the liver; 2015. Istanbul.

58. Yu ML, Lee CM, Chuang WL, Lu SN, Dai CY, Huang JF, et al. HBsAg profiles in patients receiving peginterferon alfa-2a plus ribavirin for the treatment of dual chronic infection with hepatitis B and C viruses. In fect Dis. 2010;202(1):86-92. doi: 10.1086/653209. [PubMed: 20482252].

59. Xie QCH, Zhang NP, Qi X, Chen L, Guo S. Addition of peginterferon ALFA 2B during long term nucleos(t)ide analogue therapy increases HBEAG seroconversion and hbsag decline-week 48 results from a multicenter randomized controlled trial (pegon study). 24th Annual Conference of the Asian Pacific Association for the study of the liver; 2015. Istanbul. .

60. Chan HLYK, Papatheodoridis GYMF, Chien RN, Kwan P. Characterization of HBsAg decline in the Tenofovir disoproxil fumarate (TDF) and peginterferon alfa $2 \mathrm{~A}$ (PEG) combination study for chronic hepatitis $\mathrm{B}$ (CHB). 24th Annual Conference of the Asian Pacific Association for the study of the liver; 2015. Istanbul. .

61. Heathcote EJ, Marcellin P, Buti M, Gane E, De Man RA, Krastev Z, et al. Three-year efficacy and safety of tenofovir disoproxil fumarate treatment for chronic hepatitis B. Gastroenterology. 2011;140(1):132-43. doi: 10.1053/j.gastro.2010.10.011. [PubMed: 20955704].

62. Lucifora J, Xia Y, Reisinger F, Zhang K, Stadler D, Cheng X, et al. Specific and nonhepatotoxic degradation of nuclear hepatitis B virus cccDNA. Science. 2014;343(6176):1221-8. doi: 10.1126/science.1243462. [PubMed: 24557838].

63. Wu D, Han M, Ning Q. An integration of deep viral suppression with sequential immune modulation (cocktail therapy) to restore antiviral capacity: the future of chronic hepatitis B?. J Hepatol 2015;62(1):240-1. doi: 10.1016/j.jhep.2014.10.002. [PubMed: 25308175].

64. Li G, Jiang G, Lu J, Chen S, Cui L, Jiao J, et al. Inhibition of hepatitis $\mathrm{B}$ virus cccDNA by siRNA in transgenic mice. Cell Biochem Biophys. 2014;69(3):649-54. doi: 10.1007/s12013-014-9847-1. [PubMed: 24569930]. 